\title{
INTERVENÇÃO EM ESTIMULAÇÃO MULTISSENSORIAL E SNOEZELEN
}

\author{
M. Fátima Martins Simões Paulo \\ Universidad de Extremadura \\ mariafatimapaulo@gmail.com \\ J. Inmaculada Sánchez Casado \\ Universidad de Extremadura \\ iscasado@unex.es
}

Recepción Artículo: 18 mayo 2021 Admisión Evaluación: 18 mayo 2021 Informe Evaluador 1: 23 mayo 2021

Informe Evaluador 2: 27 mayo 2021

Aprobación Publicación: 02 junio 2021

\section{RESUMO}

A intervenção em estimulação multissensorial e Snoezelen, além de ser utilizada como promotora de relaxamento e lazer com as crianças, é também usada noutras idades e tem um grande impacto na qualidade de vida de quem as vivencia.

Durante o período de confinamento, devido ao Covid-19 nos meses de janeiro, fevereiro e março, como docente de educação especial a minha intervenção foi ao nível da terapia multissensorial Snoezelen com um aluno que sofre de Perturbação do Espectro do Autismo.

A Perturbação do Espectro do Autismo (PEA) é uma perturbação do neurodesenvolvimento que se caracteriza por dificuldades na comunicação e interação social, associadas a comportamentos repetitivos.

Esta técnica usa ainda vários materiais para efeitos terapêuticos e pedagógicos que tem grande importância e benefícios ao nível da intervenção da educação especial e noutros contextos da escola inclusiva.

Palavras-chave: intervenção; estimulação; multissensorial; snoezelen; Covid-19

\section{ABSTRACT}

Intervention in multisensory stimulation and Snoezelen. The intervention in multisensory stimulation and Snoezelen, in addition to being used as a promoter of relaxation and leisure with children, is also used at other ages and has a great impact on the quality of life of those who experience them.

During the period of confinement, due to Covid-19 in the months of January, February and March, as a special education teacher, my intervention was at the level of multisensory therapy Snoezelen with a student who suffers from Autism Spectrum Disorder.

Autism Spectrum Disorder (PEA) is a neurodevelopmental disorder that is characterized by difficulties in communication and social interaction, associated with repetitive behaviors. 


\section{INTERVENÇÃO EM ESTIMULAÇÃO MULTISSENSORIAL E SNOEZELEN}

This technique also uses various materials for therapeutic and pedagogical purposes that are of great importance and benefits in terms of the intervention of special education and in other contexts of the inclusive school.

Keywords: intervention; multisensory; snoezelen stimulation. Covid-19

\section{INTRODUÇÃO}

Snoezelen, desde a sua origem, se entende como: "UM LUGAR, UMA ATIVIDADE, UMA FILOSOFIA:

UMA MANEIRA DE ENTENDER O OUTRO DIFERENTE COMO SUJEITO"

Snoezelen é um ambiente especificamente equipado que transmite aos seus visitantes um sentimento agradável de processos de auto-regulação. Através de uma sala equipada e usada de acordo com as necessidades específicas de cada pessoa, consegue-se a estimulação de intervenções terapêuticas e pedagógicas, tanto como se fortalece as relações pessoais entre terapeuta e paciente. Snoezelen pode ser aplicado com grande êxito na área de pacientes, deficientes e não deficientes. (Fundação Alemã de Snoezelen, 1999).

Durante o presente ano letivo participei numa ação de formação online sobre a intervenção em estimulação multissensorial e Snoezelen.

A minha motivação para esta ação de formação surgiu há bastante tempo, pois o método.

Snoezelen e respetivas potencialidades em termos da intervenção nos alunos com autismo e outras problemáticas, requer conhecimento efetivo sobre este tipo de intervenção.

Esta ação foi bastante enriquecedora, uma vez que permitiu compreender melhor o Ambiente Snoezelen; sendo que este não tem de ocorrer somente nas denominadas salas Snoezelen, pois trata-se de uma filosofia, que pode ser recriada onde queiramos, desde que obedeçamos aos seus princípios.

A Natureza, por exemplo, pode só por si, ou com alguns adereços, proporcionar um ambiente Snoezelen e permitir desenvolver determinados objetivos associados ao mesmo.

A estimulação sensorial, além de ser utilizada como promotora de relaxamento e lazer com as crianças, facilitadora de aprendizagens ou descobertas, de emoções e reações; é também usada em pessoas de diferentes idades, especialmente pessoas idosas que sofrem de demência e outros diagnósticos. E ainda numa vertente preventiva ou de alívio da dor, a qual tem um grande impacto na qualidade devida de quem as vivencia.

Durante o período de confinamento, devido ao Covid-19, todos os alunos sentiram as suas rotinas alteradas, o que agravou as suas vivências. E em particular os alunos da Educação Inclusiva, que por si só já sofrem de várias patologias, em particular alunos com diagnósticos mais graves, tais como: Hiperatividade, Défice Intelectual e Perturbação do Espectro do Autismo.

A Perturbação do Espetro do Autismo (PEA) é uma perturbação do neuro-desenvolvimento que se caracteriza por um conjunto de dificuldades nas áreas da comunicação/interação social e interesses e comportamentos restritos e repetitivos. Mais do que um conjunto fixo de características, esta perturbação parece manifestar-se através de uma variedade de combinações possíveis de sintomas, num contínuo de gravidade de maior ou menor intensidade, pelo que se fala atualmente em Perturbações do Espectro do Autismo (PEA). Não obstante estes indivíduos manifestarem um conjunto de sintomas que permitem realizar um diagnóstico clínico, não existem duas pessoas afetadas da mesma forma e por isso podem ser muito diferentes entre si, não constituindo um grupo homogéneo.

As Perturbações do Espectro do Autismo são alterações crónicas do neurodesenvolvimento que partilham várias características e incluem o Autismo clássico, a síndrome de Asperger (autismo mais ligeiro e com melhor prognóstico), a perturbação global do desenvolvimento sem outra especificação e o Autismo atípico,(Lima, 2015). Inserem-se nas Perturbações Globais do Desenvolvimento Psicológico das crianças e adolescentes.

A causa das perturbações do espectro do autismo não estão completamente esclarecidas e parecem resultar de uma combinação complexa de fatores genéticos, pré-natais (como alterações hormonais, exposição a substâncias tóxicas e infeções), relacionados com o parto (como a prematuridade, baixo peso, infeções e traumatismos) e também psicológicos. De salientar que não há relação com a nacionalidade, etnia, classe social ou ações educacionais dos pais. 


\section{SINTOMAS AS PERTURBAÇÕES DO ESPECTRO DO AUTISMO}

0 autismo manifesta-se habitualmente nos primeiros 3 anos de vida, particularmente na faixa etária dos 15 meses aos 3 anos, altura em que é esperada uma grande evolução nas competências de comunicação das crianças (Lima, 2012).

Algumas condições com sintomas mais leves podem tornar-se evidentes apenas mais tarde (depois dos 3 anos), quando passa a existir uma maior exigência em relação ao comportamento social da criança/adolescente.

No entanto, é necessária uma avaliação detalhada e integrada para confirmar o significado destes sintomas. Algumas crianças têm sintomas isolados que não correspondem necessariamente ao diagnóstico de PEA.

Os sinais de alarme incluem:

- Não apontar com o dedo para pedir ou mostrar aos 16 meses

- Usar pouco o contacto ocular para fazer pedidos e na comunicação em geral

- Não responder ao seu nome

- Não se envolver em gracinhas e jogos de imitação (ex: bater palminhas)

- Ser muito independente em idade precoce, isto é, não solicitar/envolver os outros

- Apresentar comportamentos repetitivos como rodar objetos ou alinhar formas e cores

- Não usar frases de duas palavras aos dois anos ou deixar de dizer palavras que já dizia

Estas perturbações manifestam-se através alterações principalmente em três domínios:

- da interação social, com tendência para o isolamento;

- da comunicação verbal, com atraso no desenvolvimento da linguagem, ecolália (repetição, "fala de papagaio"), uso alterado da forma negativa, inversão dos pronomes nas frases, entre outras; mas também da comunicação não verbal com voz monótona, diminuição da expressividade facial e gestos inadequados;

- do pensamento e do comportamento, com redução da imaginação, da atenção e concentração, rigidez de pensamento e dificuldade na adaptação a mudança de rotinas, comportamentos ritualistas e repetitivos.

-É também frequente os doentes apresentarem interesses restritos por objetos (por exemplo um brinquedo particular), assuntos (carros, aviões...) ações (por exemplo, alinhar brinquedos e outros objetos) ou temas amplos (como história, geografia...). Podem ainda ser evidentes alterações da sensibilidade, por vezes com insensibilidade à dor e à temperatura a par de repostas aumentadas a sons, cheiros ou texturas.

\section{Como se diagnosticam?}

0 diagnóstico das Perturbações do Espectro do Autismo pode ser feito em qualquer idade mas é muito mais frequente entre os 18 e os 36 meses. Perante os sinais de suspeita, a criança poderá ser avaliada num centro multidisciplinar de Pedopsiquiatria e Pediatria do Desenvolvimento. É particularmente importante avaliar a capacidade auditiva e os atrasos de linguagem que nada têm a ver com o espectro do autismo mas que podem condicionar sintomas semelhantes. 0 diagnóstico depende da avaliação do comportamento com base em critérios estabelecidos por especialistas. A precocidade de diagnóstico é extremamente importante para que a intervenção aconteça antes dos períodos do desenvolvimento infantil que são mais propícios à aquisição de determinadas capacidades. Com efeito, de acordo com os estudos, a linguagem e as competências sociais e comportamentais desenvolvem-se maioritariamente até aos 8 anos de idade.

Têm havido importantes avanços no campo da investigação em torno do desenvolvimento precoce das PEA. No sentido de saber 0 estado da arte nesta matéria, um painel multidisciplinar de clínicos e investigadores especialistas em PEA e perturbações do neurodesenvolvimento (Zwaigenbaum L. et al., 2011) completaram uma revisão da literatura e chegaram a um consenso baseado na evidência atual para responder à seguinte pergunta: "Quais são os primeiros sinais e sintomas de PEA em crianças $\leq 24$ meses de idade que podem ser usados para identificação precoce desta perturbação?”. A investigação foi concluída em outubro de 2010 e atualizada posteriormente em dezembro de 2013. As conclusões da revisão foram resumidas em afirmações que refletem o conhecimento atual em relação aos sinais precoces da PEA. 


\section{INTERVENÇÃO EM ESTIMULAÇÃO MULTISSENSORIAL E SNOEZELEN}

\section{Quais as estratégias de intervenção?}

A intervenção é sobretudo educacional, visando o desenvolvimento e treino de competências de comunicação e comportamento. Apesar de não existirem medicamentos capazes de tratar as principais alterações das Perturbações do Espectro do Autismo, os fármacos podem ser úteis no controlo de alguns sintomas acompanhantes como a ansiedade, a hiperatividade e as alterações de sono. Também, vários estudos recentes (Lima, 2012) salientam a importância de atividades complementares como música, a arte, a dança e o contacto com animais que para além de serem oportunidades de comunicação favorecem a estimulação dos sentidos (sobretudo da audição, visão e tacto) e apresentam benefícios físicos e emocionais, com redução da ansiedade e aumento da autoconfiança.

Assim, ainda que não se possa falar em cura nas Perturbações do Espectro do Autismo, é importante salientar que as intervenções terapêuticas atuais multidisciplinares e integradas, envolvendo os cuidados de saúde primários, a família e a escola, são bastante eficazes, aumentando a autonomia e potenciando o desenvolvimento.

\section{Quais o prognóstico?}

0 prognóstico das Perturbações do Espectro do Autismo é variável, sobretudo consoante o tipo particular de perturbação apresentada. Em termos gerais, as alterações ao nível da comunicação e do comportamento tendem a melhorar entre os 6 e os 10 anos de idade sendo que a aquisição da fala e a presença de capacidades cognitivas normais são indicadores favoráveis, (Filipe, 2012) Na adolescência e início da idade adulta pode haver agravamento dos sintomas que geralmente voltam a diminuir após a meia-idade.

\section{PROBLEMÁTICA DO ALUNO}

Durante o período de confinamento, devido ao Covid-19, um aluno com Perturbação do Espectro do Autismo, sentiu a sua rotina alterada, o que agravou as suas vivências. Como está constantemente a bater as mãos (palmas) e a torcer as mesmas o que lhe provoca feridas, este também coloca as mãos na boca, com alguma frequência, sendo por isso muito difícil manter as regras de higiene. Este género de conduta é típico em pessoas com esta patologia, e muito perigosa devido à situação de pandemia Covid-19, que atravessamos. A terapia Snoezelen aplicada ao aluno em questão, proporcionou-Ihe relaxamento e conforto através da música (sons), de estímulos sensoriais, texturas e aromaterapia, oferecendo-Ihe sensações de alívio.

\section{TRATAMENTO}

Como docente de educação especial a minha intervenção foi ao nível da terapia multissensorial Snoezelen aplicada a este aluno que sofre de Perturbação do Espectro do Autismo. Durante o período de confinamento em Portugal, nos meses de janeiro, fevereiro e março, 0 aluno teve aulas presenciais com a docente de educação especial e online nas outras disciplinas. 0 aluno em questão como já foi descrito, o seu estado, piorou bastante pela mudança de rotinas.

Nas aulas presencias, em sala de aula, foi aplicada a terapia Snoezelen, estas aulas foram planificadas para duas sessões por semana, entre quinze a vinte minutos cada sessão.

Em primeiro lugar temos que falar com 0 aluno e explicar que vamos para a sala snoezelen, fazer uma atividade diferente com o objetivo de relaxar e aprender. Dizer que quando entrarmos na sala vai estar silêncio e pouca luz. Mostrar uma foto/pictograma da sala. Dizer ao aluno para ir à casa de banho, e informá-lo que se quiser sair da sala, poderá pedir para o fazer. Na véspera deve ser dito ao aluno para trazer uma roupa confortável (fato de treino). Também informar que terá descalçar os sapatos à entrada, e tirar 0 casaco...

- Apenas uma luz fica acesa para iluminar a sala

- Acender uma luz em tom azul

- Acender uma vela aromática.

- Puf para o aluno se sentar.

- Bola macia. 
- Ligar a música ambiente (Compilação de música de Bach e Mozart e Tchaikovsky)

A sessão deve ser terminada de forma lenta. Informar 0 aluno que vamos terminar a sessão, baixar o volume da música até desligar. Acender a luz da sala e apagar a outra iluminação usada, sentar-se no chão e calçar os sapatos. Tirar os dados do pulsiómetro.

Realizar o registo da avaliação da intervenção.

\section{ACOMPANHAMENTO SALAS SNOEZELAN}

Os três eixos do acompanhamento:

- Relacional

- Sensorial

- Relaxamento e bem-estar

\section{- Relacional}

- A relação é um encontro entre dois sujeitos:

Isto induz a um envolvimento mutuo onde a linguagem não será necessariamente aplicada de modo verbal, mas pode passar a não verbal (um abraço). Um motor de mudança é o prazer sentido de estar lá a diversão e a motivação subjacente. "É para ser", com isto queremos dizer que é preciso adaptar-se a qualquer momento. Permitir o utente ser em vez de agir, fazer.

Respeito pela pessoa, seu ritmo, suas necessidades e expectativas. Qualidade de presença $e$ adaptação do acompanhamento

\section{- Sensorial}

A informação sensorial influencia o nosso estado tónico e emocional tendo consequências sobre as nossas condutas e os nossos comportamentos.

Fornecendo âncoras positivas nas modalidades sensoriais (ligações sensoriais, por exemplo, um cheiro, um toque, uma música ou um brilho que são associadas a experiências positivas de bem - estar) promovemos 0 despertar sensorial em (re) explorar o mundo mas num ambiente seguro.

Esta estimulação deve, evidentemente, ser adaptada às necessidades, desejos capacidades individuais, qualitativamente e quantitativamente.

Proposta de experiências sensoriais. Apresentação seletiva dos diferentes fluxos sensoriais. Ajustamento do ambiente e da criatividade

\section{- Relaxamento e bem-estar}

Ter tempo para se posicionar e centrar (estar presente e totalmente disponível), e utilizar um diálogo caloroso. Tudo isto para construir uma relação de confiança indispensável para permitir o relaxamento, baixar a ansiedade a angústia as tensões: condições par atenuar comportamentos difíceis estereotipias, automutilações, agressividade, hiperatividade...Para um melhor bem-estar em potência, pelo menos durante as sessões Snoezelen.

É necessário neste acompanhamento encontrar um ajustamento entre atividade e passividade em função dos projetos individuais e institucionais, a fim de preservar o sentido desta prática.

Descoberta do relaxamento e da descontração. Capacidade de proporcionar segurança, prazer e bem-estar.

0 espaço de estimulação sensorial deverá conter objetos, luzes, música e cheiros que estimulem os cinco sentidos (visão, audição, tato, olfato e paladar).

Sendo o mais importante é que os sentidos sejam ativados e que, a partir do sistema nervoso central, sejam experienciadas diferentes estimulações com as sensações agradáveis que daí podem decorrer. 0 espaço snoezelen deverá ser calmo e securizante para proporcionar estimulação sensorial e potenciar o relaxamento, com equi- 


\section{INTERVENÇÃO EM ESTIMULAÇÃO MULTISSENSORIAL E SNOEZELEN}

pamentos especiais e adequados, sendo que a música e as luzes escurecidas apresentam um papel facilitador e preponderante neste mesmo espaço (Verheul, 2014).

\section{Salas Snoezelen: conheça os Benefícios da Intervenção Multissensorial}

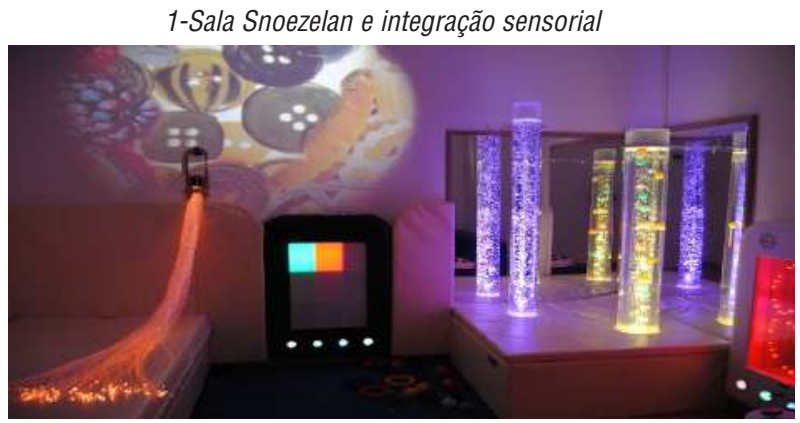

As salas Snoezelen proporcionam uma intervenção multissensorial única, completa e significativa para crianças, jovens e adultos com vários tipos de perturbações e problemáticas, nomeadamente:

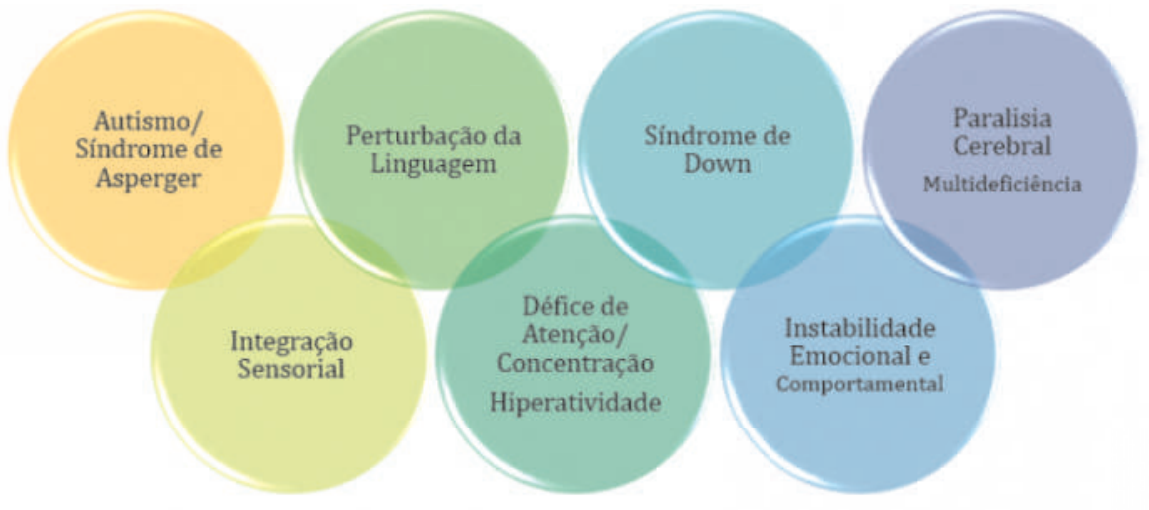

\section{ABECEDÁRIO DA EDUCAÇÃO}

De facto, 0 ambiente criado nestas salas facilita uma abordagem multissensorial ao nível da perceção e memória visual, auditiva, tátil, gustativa e olfativa. Para além disso, proporciona momentos de grande conforto, relaxamento, bem-estar e prazer, num ambiente terapêutico, claramente calmo, acolhedor e controlado.

Na verdade, estas salas permitem a criação de uma enorme variedade de atividades tendo em conta as características, as necessidades e o ritmo de cada pessoa

\section{Benefícios de uma intervenção multissensorial}

A intervenção multissensorial permite 0 desenvolvimento de competências cognitivas, comunicativas, sociais, motoras e educacionais (Stella,2008). Permite ainda: 

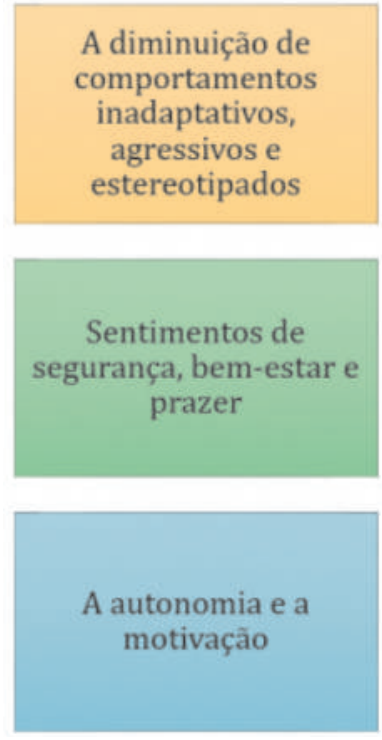
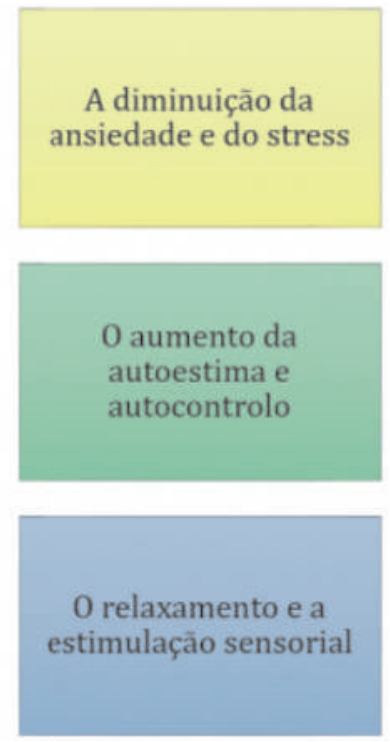
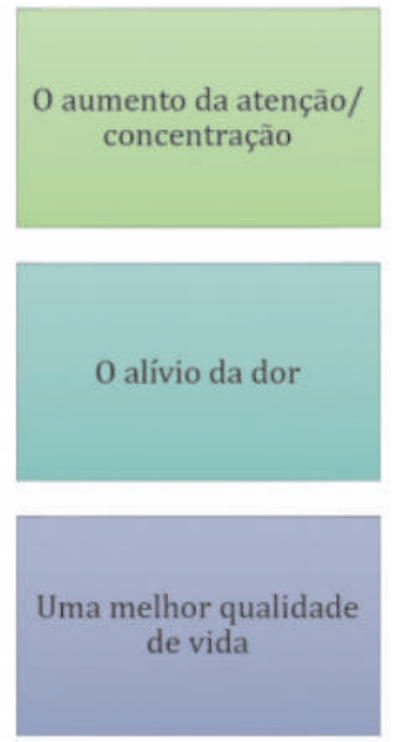

A função principal da sala Snoezelen é criar um espaço calmo e seguro, no qual a pessoa possa desfrutar de experiências sensoriais positivas e de momentos de relaxamento.

Estas salas proporcionam várias experiências únicas e adaptadas a cada tipo de intervenção. As diferentes intervenções concedem uma grande quantidade de estímulos sensorias, o que torna estas experiências distintas e extremamente enriquecedoras

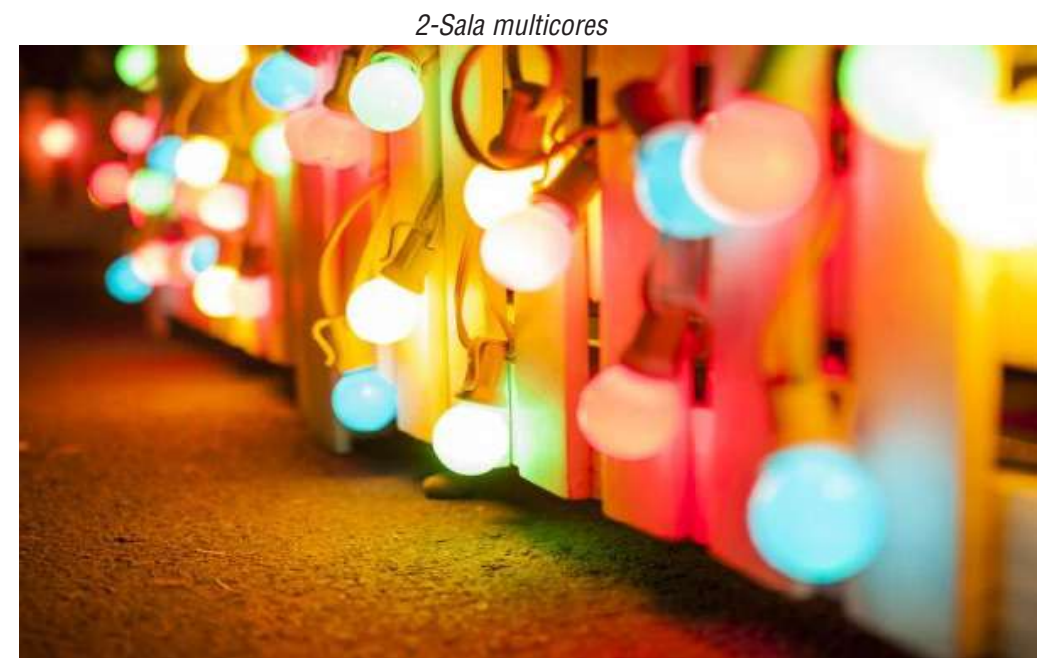




\section{INTERVENÇÃO EM ESTIMULAÇÃO MULTISSENSORIAL E SNOEZELEN}

\section{Ficha de avaliação da sessão em sala Multissensorial}

\section{-Grau de relaxamento:}

Refere-se a um estado geral de quietude e calma. Param os movimentos repetitivos, o nível de atividade e a agitação reduzem se e entra num estado perto das sonolência, embora fique desperto, com um certo nível de alerta.

- Condutas de nível 0: permanece inquieto e agitado, sem mostrar nenhuma tranquilidade.

-Condutas de nível 3: mantém- se imóvel, estado perto da sonolência.

\section{-Nível Motivacional:}

Refere-se a como a avaliamos o estado interno do sujeito em relação à sua presença na sala Multissensorial. Se achamos que quer ir, se está presente com agrado, se quer permanecer mais tempo na sala de aula, etc.

- Condutas de nível 0: não quer estar na sala, não colabora, não mostra interesse por nenhum equipamento, etc.

-Condutas de nível 3: desfruta da atividade, está contente consigo, etc.

\section{-Bem-estar emocional:}

Refere-se aos sinais que mostra de estar com satisfação, sente prazer e gosta do vínculo com o adulto. Sorri e mostra sensações gerais de disfrute e tranquilidade.

- Condutas de nível 0: expressões de raiva, tristeza, desagrado, etc. Permanece bastante tempo descontente, aborrecido, etc.

-Condutas de nível 3: expressões de alegria, sorrisos, risos, aumento de vocalizações, etc.

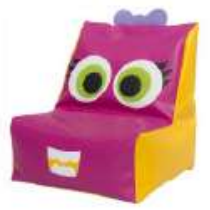

3-Puf

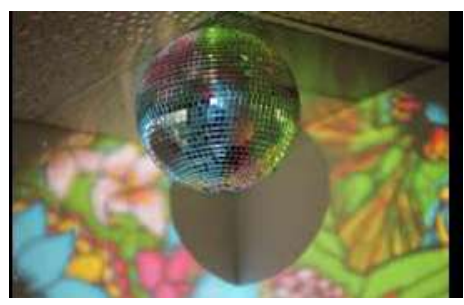

4-Bola de espelhos (rodar lentamente)

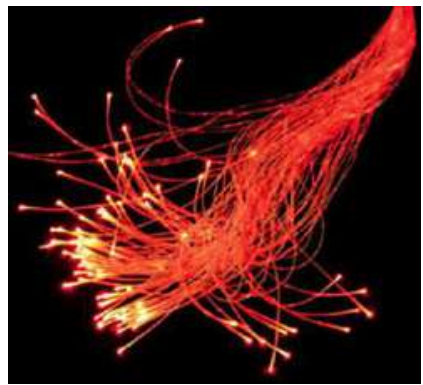

5-Baloiço

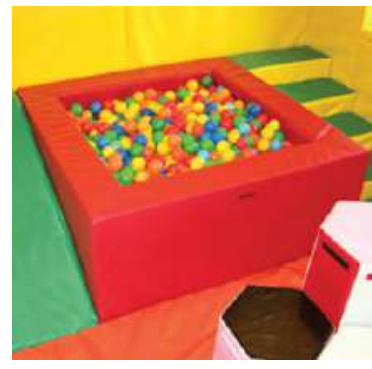

6-Cortina de fibra óptica (molho de fibras ópticas)

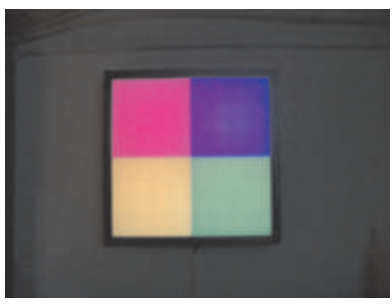

5-Tapete

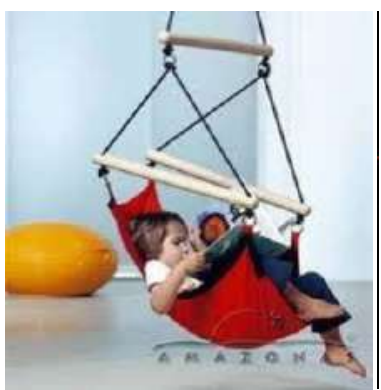

7-Tanque de bolas 


\section{RESULTADOS}

Entrar na sala e observar a reação do aluno. Falar calmamente. Introduzir as experiências sensoriais, uma de cada vez e observar as reações do aluno e desligar o equipamento que causa desconforto. Estar perto do aluno em todos os momentos, sem nunca o deixar "sozinho". Utilizar música relaxante e proporcionar momentos de silêncio durante a atividade.

Iniciar a sessão com atividades mais estimulantes e terminar com atividades mais relaxantes na última terça parte do tempo.

0 aluno também usufruiu da coluna de bolhas que é bastante relaxante, para observar e sentir a vibração temos desligar a música para se concentrar apenas no som da água. Mudar a cor da luz para tons lilás e verde. A seguir ligar a música relaxante (tons binaural).

Levar 0 aluno para o meio da sala. Realizar um relaxamento guiado, usando uma voz calma e em tom baixo.

Este aluno reagiu de forma muito positiva melhorando a sua postura, diminuindo a ansiedade e conseguindo um maior controlo das mãos, desde o primeiro mês.

0 aluno diminuiu os batimentos das mãos (palmas), melhorou também o torcer das mesmas e diminuiu também a quantidade de vezes que levava as mãos à boca. Melhorando por isso toda a sua postura durante este momento tão delicado e perigoso que todos nos vivenciamos com o Covid-19, e sobretudo os alunos da educação inclusiva.

0 método Snoezelen aplicado nestas salas oferecem uma vasta quantidade de estímulos, de forma individual ou combinada, cruzando música, sons, luzes, cores, vibrações suaves, texturas e aromas. Este ambiente proporciona e permite estimular: sentidos primários sem necessidade de recorrer às capacidades intelectuais, privilegiando as sensoriais.

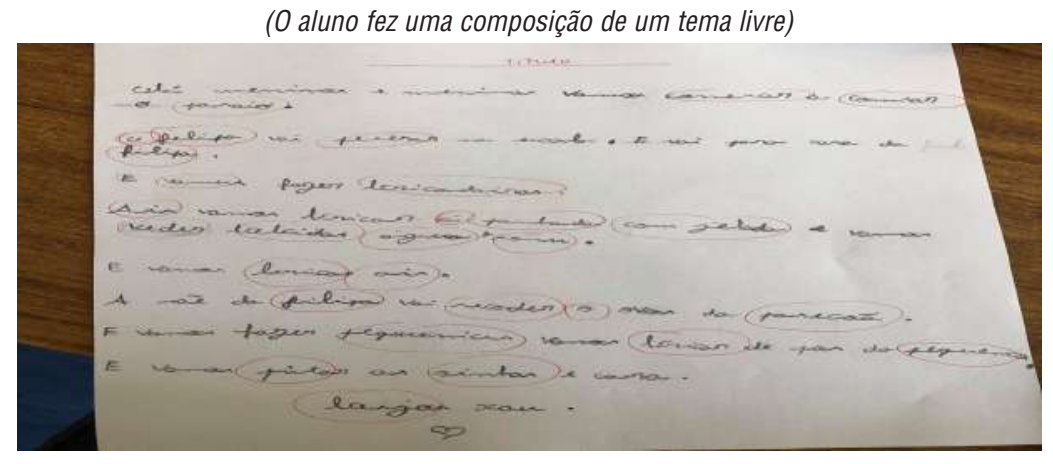

(0 aluno reproduz um desenho que visualiza durante um determinado tempo)

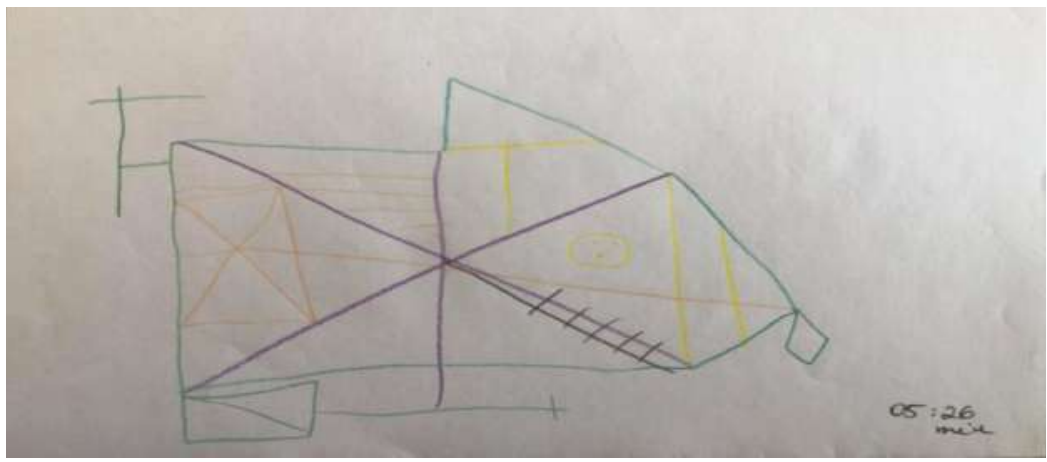




\section{INTERVENÇÃO EM ESTIMULAÇÃO MULTISSENSORIAL E SNOEZELEN}

Como resultado final indicar : RESPEITAR SEMPRE A PESSOA

- Não forçar situações

- Respeitar os ritmos e preferências.

- Procurar e conseguir a comunicação e a interação.

\section{CONCLUSÕES}

Devemos ter sempre em consideração, cada aluno como caso único e individual, devendo por isso, que as estratégias a adotar serem diferenciadas.

Através da estimulação multissensorial, aplicada de forma ajustada às capacidades presentes, facilita-se as possibilidades de ação da pessoa, e as respostas adaptadas á situação.

Todas as capacidades são observadas e exploradas com a pessoa numa postura correta e mais adequada possível para ela.

As Perturbações do Espectro do Autismo são alterações crónicas do neurodesenvolvimento graves e bastante frequentes. Um diagnóstico precoce iria melhorar o prognóstico por permitir uma intervenção terapêutica mais eficaz.A maior parte das crianças com perturbação do espectro do autismo terá uma vida normal, apesar de poder continuar a necessitar de apoio ao longo do tempo.

No Agrupamento que estou a trabalhar, vou estudar as hipóteses de adquirir mais equipamento, a fim de poder criar ambientes mais ricos e estimulantes, para os vários tipos de desafios com que nos deparamos no nosso dia a dia, numa escola onde queremos que, efetivamente, a inclusão seja cada vez mais uma realidade concretizada.

Por outro lado, seria enriquecedor que em futuros estudos de investigação na área as observações feitas pudessem averiguar os efeitos do snoezelen num período mais alargado de tempo e acompanhar outros alunos noutras atividades, como também incidir sobre participantes noutras problemáticas.

Os investigadores ainda não encontraram um sinal comportamental isolado ou uma única trajetória neurodesenvolvimental preditivos de todos os diagnósticos de PEA. Dada a heterogeneidade da expressão clínica da PEA, é pouco provável que um único sinal comportamental seja universalmente encontrado em todas as crianças com a perturbação ou que sirva de marcador definidor de um diagnóstico futuro de PEA. Uma investigação futura poderá melhorar a previsão do risco de PEA através da análise de combinações de sintomas que representem índices de risco cumulativo.

Para que a intervenção junto da criança tenha sucesso é necessário que se estabeleça uma aliança terapêutica com as famílias. Esta, servirá de referência quando o caminho a percorrer parecer demasiado tumultuoso e os resultados incertos e servirá para que o desanimo, a dúvida e a desmotivação não de abatam sobre famílias e técnicos.

\section{REFERÊNCIAS BIBLIOGRÁFICAS}

Filipe, C.N. (2012) Autismo: conceitos, mitos e preconceitos. Lisboa: Verbo.

Hewitt (2010) Compreender o Autismo- Estratégias para alunos com Autismo nas escolas regulares (J. Almeida, Trad.). Porto: Porto Editora.

Lima, C. B. (coord.) (2012) Perturbação do Espectro do Autismo: Manual prático de intervenção. Lisboa: Lidel Edições Técnicas

Lima C.B (2015) Perturbações do neurodesenvolvimento: Manual de orientações Dagnósticas e Estratégias de Intervenção. Lisboa: Lidel Edições

Stella, M.A.P.(2008) Snoezelen/MSE- Um caminho para o mundo Sensorial: Gráfica Capital: PR Brasil

Verheul, A. (2014) Snoezelen - nothing has to be done, everything is allowed in M. Sirkkola (Ed.), Everyday Multisensory Environments, Wellness Technology and Snoezelen. Hämeenlinna: HAMK university of Applied Sciences, Visamaki, R.

Zwaigenbaum L, et al.( 2011) Recurrence risk for autism spectrum disorders: a baby siblings research consortium study. Pediatrics. 
Federação Portuguesa para as Perturbações do Desenvolvimento e Autismo.

https://educares.com.pt/criancas-e-adolescentes/desenvolvimento-infantil/perturbacao-do-espectro-do-autismo/http://metis.med.up.pt/index.php/Perturba\%C3\%A7\%C3\%B5es_do_espectro_do_autismo https://educamais.com > snoezelen-o-que-e

https://www.appc-faro.org.pt > outros-servicos > snoeze.

https://www.youtube.com/watch?v=eap0oA46HPM

https://www.youtube.com/watch?v=acQS2Fef8tUPERTURBAÇÕES DO NEURODESENVOLVIMENTO 
